\title{
ANÁLISE DA TEORIA DA ESTOCAGEM SOBRE A BASE DOS CONTRATOS FUTUROS DE SOJA NO BRASIL
}

\author{
SILVEIRA, Gabriel Agnesini da ${ }^{1}$ \\ AMBROZINI, Marcelo Augusto ${ }^{2}$
}

RESUMO: Esta pesquisa teve como objetivo avaliar o impacto das variáveis da teoria de estocagem, como custo de oportunidade e estoque, sobre a base dos contratos futuros de soja negociados na BM\&F-Bovespa, para um período de outubro de 2013 a março de 2017, com dados diários. Foi proposta uma análise semelhante à de Fama e French (1987) a qual verificou o impacto dos custos de oportunidade do capital e de uma proxy para o estoque de soja, visando capturar os custos de estocagem e o benefício de conveniência, derivados da teoria da estocagem. Verificou-se que o custo de oportunidade dos agentes de mercado impacta positivamente a base. Da mesma forma, o estoque também impacta de forma positiva a base. Os resultados encontrados estão em conformidade com a teoria de estocagem proposta por Working (1948). Assim, a principal contribuição do trabalho é fornecer à literatura evidências empíricas que sustentem o comportamento da base de soja no Brasil.

Palavras-chave: Mercado futuro. Commodities agropecuárias. Base. Soja.

\section{ANALYSIS OF THE STORAGE THEORY ON THE BASIS OF FUTURE SOYBEANS CONTRACTS IN BRAZIL}

SUMMARY: The study aimed to evaluate the impact of the "Theory of Storage" variables based on the soybean futures contracts traded on BM\&FBOVESPA for a period of five years with daily data, from October 2013 to March 2017. An analysis similar to that of Fama and French (1987) was proposed, which verified the impact of the opportunity costs of capital and a proxy for the soybean stock, aiming to capture the storage costs and the benefit of convenience, derived from the theory of storage. It was verified that the opportunity cost of market agents has a positive impact on the basis, in the same way, the stock also has a positive impact on the basis. The results found are in accordance with the "Theory of Storage" proposed by Working (1949). Thus, the main contribution of the work is to provide the literature with empirical evidence to support the behavior of the soybean basis in Brazil.

Keywords: Future Market. Agricultural Commodities. Basis. Soybean.

\section{INTRODUÇÃO}

O presente trabalho teve como principal objetivo analisar o comportamento da "base" nos contratos futuros da commodity agrícola soja no Brasil. A "base" é tratada na literatura como o diferencial entre o preço à vista e preço futuro da mercadoria em questão (FARHI, 1998) ou, também, como a diferença entre dois preços futuros com vencimentos diferentes (FAMA; FRENCH, 1987).

A teoria abordada pelo trabalho sobre a base é chamada de Teoria da Estocagem "Theory of Storage", de Kaldor (1939), Working (1948), Brennan (1958) e Telser (1958). Essa teoria afirma que o

\footnotetext{
${ }^{1}$ Mestre em Controladoria e Contabilidade pela Faculdade de Economia, Administração e Contabilidade de Ribeirão Preto da Universidade de São Paulo - FEA-RP/USP

${ }^{2}$ Professor Doutor do Departamento de Contabilidade da Faculdade de Economia, Administração e Contabilidade de Ribeirão Preto (FEA-RP), da Universidade de São Paulo (USP). Professor do Programa de Pós-Graduação em Controladoria e Contabilidade (PPGCC) da FEA-RP/USP
} 
diferencial de preços (base) deve ser explicado pelos custos de armazenar a mercadoria de uma data a outra, dentre esses custos, têm-se: o custo de oportunidade do capital empregado no processo, os custos de estocagem e o rendimento de conveniência, que é derivado do benefício em possuir o estoque da mercadoria. Existe outra teoria chamada na literatura de "Normal Backwardation", que foi desenvolvida inicialmente por Keynes (1930). Essa teoria propõe que a diferença entre os preços à vista e futuro deve ser compensada também por um prêmio de risco.

Sobre os preços de mercado futuros de commodities, Pinto (2015) afirma que o mercado futuro será neutro se a "base" for equivalente aos custos de carregamento. Assim, se tais valores diferirem, o mercado futuro estará em contango ou backwardation. Nos mercados em contango, o preço futuro excede o preço spot adicionado aos custos de carregamento e o detentor de posições vendidas incorre em prêmio, têm-se, desse modo, estímulos para a manutenção de estoques. Nos mercados em backwardation, o preço spot adicionado aos custos de carregamento excede o preço futuro, então, os detentores de posições vendidas incorrem em desconto, não há estímulos para a manutenção de estoques. Portanto, mercados em contango são condizentes com estoques superavitários, ao passo que mercados em backwardation associam-se à escassez de estoques.

Keynes (1930) acreditava que em condições normais de mercado a grande demanda de hedgers de venda para transferir o risco de preço levaria o preço futuro estar abaixo do preço spot previsto, e o preço à vista excede o preço a prazo, isto é, há atraso (backwardation), e, por isso a teoria ficou chamada de "Normal Backwardation".

Assim, o primeiro trabalho a utilizar ambas as teorias - estocagem e backwardation - foi o de Fama e French (1987). Esses autores encontraram evidências empíricas mais consistentes a favor da teoria da estocagem, desta forma, o presente trabalho busca verificar a presença das variáveis da teoria de estocagem no mercado futuro da soja no Brasil por meio de uma metodologia similar a de Fama e French (1987).

Uma vez identificada a base teórica da pesquisa, cabe mostrar o cenário econômico no qual ela está inserida. As atividades agropecuárias em geral conferem alto risco ao investidor, para Bignotto, Barossi Filho e Sampaio (2004), empresas que negociam commodities agrícolas enfrentam variações nem sempre previsíveis na produção e no preço. Além disso, são acrescidos fatores climáticos, períodos sem retorno de determinadas culturas, alto investimento, alta alavancagem e perecibilidade dos produtos. Para mitigar parte dos riscos advindo das flutuações de preços, o produtor ou o transformador da soja pode, por meio do hedge, fazer uso do mercado futuro na bolsa para se proteger. O próprio site da BM\&FBOVESPA afirma que o contrato futuro de soja foi desenvolvido com o intuito de gerenciar o risco de oscilação de preço, sendo utilizadas pelos participantes do mercado, como produtores, indústria, tradings, dentre outros.

Entender o comportamento da "base" é importante e está associado ao hedge, pois ela embute em si informações dos dois preços, futuro e à vista. Nas operações de hedge os agentes do mercado compram ou vendem contratos futuros, ao mesmo tempo em que realizam atividades contrárias no mercado físico. De acordo com Farhi et al. (1998), a operação de cobertura de riscos do produtor ou de um agente que possua uma posição comprada no mercado à vista é conhecida como "hedge de venda", já a do transformador ou de todo agente com posição vendida no mercado à vista, é denominada "hedge de compra".

Além de possibilitar a realização de operações de hedge, segundo Farhi et al. (1998), esses mercados constituem o instrumento ideal para a especulação ao permitir acesso fácil e direto aos mecanismos de alavancagem. A definição mais aceita de especulação foi descrita por Kaldor, em 1939,

Nucleus,v.15,n.2,out.2018 
como sendo a compra (ou venda) de mercadorias visando à revenda (ou recompra) em uma data futura, sendo que o motivo de tal ação é a expectativa de mudança futura nos preços, e não uma vantagem derivada de seu uso ou qualquer tipo de transformação ou transferência de um mercado para outro.

Agentes de mercado comumente apostam em suas movimentações por meio de operações de arbitragem, ou seja, operações em que o agente compra um ativo e vende o outro na expectativa de mudança no diferencial de preço. Uma situação parecida com a do arbitrador é a do produtor de soja, que terá o produto físico na colheita (comprado) e irá realizar a venda futura de soja utilizando um contrato futuro; ou de um transformador, que faz a compra futura de soja e precisará do produto físico para processar no futuro, sendo que estes ficam expostos ao risco de base em ambos os casos descritos. Duarte Júnior (2001) completa que para entender e medir possíveis perdas causadas por flutuações no mercado futuro é necessário identificar e quantificar o mais precisamente possível as volatilidades e correlações das variáveis que causam impactos à dinâmica dos preços.

Diante do exposto sobre a importância do mercado de derivativos, seja utilizando o hedge com finalidade de cobertura de riscos, ou por meio de operações de arbitragem, tornam-se necessários maiores esclarecimentos a respeito de fatores que afetam a diferença temporal de preços, ou seja, a base.

Após a discussão acerca do objetivo proposto no trabalho e a importância do fenômeno de pesquisa para os agentes de mercado, surge a seguinte questão de pesquisa: a variável base dos contratos de soja é afetada pelas variáveis da teoria da estocagem?

Portanto, foram testadas neste trabalho as seguintes hipóteses:

$H_{1}$ : O custo de oportunidade no mercado impacta positivamente a base dos contratos futuros de soja no Brasil.

$\boldsymbol{H}_{2}$ : O estoque impacta negativamente a base dos contratos futuros de soja no Brasil.

Foi escolhida para esta análise uma commodity agrícola devido à importância que esta cadeia de negócios tem no Brasil.

De acordo com a Confederação da Agricultura e Pecuária do Brasil (CNA), o setor agropecuário liderou a economia brasileira em 2016, mesmo tendo atravessado uma crise política e ainda dificuldades conjunturais. O agronegócio aumentou sua participação no Produto Interno Bruto (PIB) de 21,5\% para $23 \%$ e passou a representar $48 \%$ das exportações totais do país. Em um dado mais recente divulgado pela Secretaria de Relações Internacionais do Agronegócio, ligada ao Ministério da Agricultura Pecuária e Abastecimento (MAPA), tem-se que, em abril de 2017, as exportações do agronegócio brasileiro alcançaram o montante de US\$ 8,66 bilhões, o que representou um crescimento de 7,3\% em comparação aos US\$ 8,07 bilhões exportados em abril do ano anterior, atingindo 49,0\% do total das vendas externas brasileiras no mês.

Dentre as commodities agrícolas com maior participação na balança comercial, em relação ao período de 2016, segundo dados do MAPA está o complexo soja, representando 52,5\% das exportações; as carnes, 12,4\%; produtos florestais, 9,9\%; complexo sucroalcooleiro, 9,2\% e o café, com participação de $4,5 \%$. O primeiro lugar fica com o complexo soja, que em valores absolutos é mais de quatro vezes a exportação de carnes, a segunda posição.

A soja foi a commodity escolhida não apenas devido a sua participação na arrecadação com as exportações de soja em grãos e derivados, mas também pela sua importância no setor do agronegócio no país. Segundo o site da BM\&F-BOVESPA,a soja possui uma cadeia produtiva muito abrangente ao fornecer insumos para os setores de alimentação animal, produção de biodiesel, saúde e industrial 


\section{FUNDAMENTAÇÃO TEÓRICA}

A diferença entre o preço futuro e o preço à vista (preço spot) de uma commodity, ou simplesmente a diferença de dois preços futuros em datas diferentes é denominada de base na literatura de finanças. Existem duas teorias que buscam explicar essa diferença de preços: a teoria proposta por Keynes (1930), originada da teoria do "normal backwardation", e a teoria da estocagem proposta inicialmente por Kaldor (1939) e Working (1948).

A teoria de estocagem é construída sob a ótica de valor de tempo e do benefício de segurar a mercadoria fisicamente. A base é explicada em função dos custos de manutenção intertemporal do produto estocável, que são: os custos de armazenar a mercadoria de uma data a outra, o custo de oportunidade do capital empregado no processo e do chamado rendimento de conveniência que deriva do benefício de possuir o estoque da mercadoria. Já a teoria proposta por Keynes (1930) origina da teoria do "normal backwardation", onde o diferencial de preço deve ser formado principalmente por um prêmio de risco.

Em síntese, sobre "normal backwardation", Keynes (1930) ressalta o risco financeiro oferecido pela necessidade de se armazenar estoques de um período para o outro e sugere que os mercados futuros existem para facilitar o hedge. $\mathrm{O}$ autor afirma que se a oferta e a procura forem equilibradas, o preço à vista deve exceder o preço no futuro pelo montante que o produtor está disposto a sacrificar para se "proteger", a fim de evitar o risco de flutuações de preços durante o seu período de produção.

Assim, em condições normais, o preço à vista excede o preço a prazo, isto é, há atraso (backwardation). Em outras palavras, o preço normal de fornecimento à vista inclui uma remuneração pelo risco de flutuação dos preços durante o período de produção, enquanto o preço a prazo a exclui essa remuneração. O especulador de compra (venda) percebe o prêmio ao recusar-se a comprar um contrato do hedger venda (compra), exceto pelo preço abaixo (acima) do qual o preço futuro deve se aproximar. A teoria afirma que a grande demanda de hedgers de venda para transferir o risco de preço leva o preço futuro estar abaixo do preço spot previsto, o que garante um prêmio de risco ao especulador.

Uma vez que a literatura observada e também o trabalho de Fama e French (1987) enxergam que esse diferencial de preço responde mais fortemente as variáveis de estocagem, será explorada neste trabalho uma metodologia que testa a presença da teoria da estocagem no mercado de soja no Brasil, por isso, será dada mais ênfase nesta teoria, conhecida na literatura internacional como "theory of storage".

A literatura será discutida com foco no modelo teórico da teoria da estocagem proposta por Fama e French (1987), onde $\mathrm{F}(\mathrm{t}, \mathrm{T})$ é o preço futuro no tempo t para entrega em $\mathrm{T}$ e $\mathrm{S}(\mathrm{t})$ é o preço à vista em t. A teoria prediz que o retorno de se comprar a mercadoria em t e vendê-la para entrega em $\mathrm{T}$, ou seja, a base $\mathrm{F}(\mathrm{t}, \mathrm{T})$ - $\mathrm{S}(\mathrm{t})$, é igual aos juros corridos, $\mathrm{S}(\mathrm{t}) \mathrm{R}(\mathrm{t}, \mathrm{T})$, somado ao custo marginal de estocagem, $\mathrm{W}(\mathrm{t}$, $\mathrm{T})$, menos o rendimento marginal de conveniência, $\mathrm{C}(\mathrm{t}, \mathrm{T})$. Tal como se apresenta a seguir na equação (1):

$$
F(t, T)-S(t)=S(t) R(t, T)+W(t, T)-C(t, T)
$$

Kaldor (1939) em seu artigo seminal tratou esse diferencial de preço sob o contexto da especulação e forneceu informações relevantes sobre o que ficou conhecida como a teoria da estocagem. Ele dizia que se as expectativas fossem bastante certas, a atividade especulativa ajustaria os preços de modo que a diferença entre o preço esperado e o preço atual seria igual à soma do custo de juros e do 
custo de manutenção (limpeza, estocagem, transporte), e ainda menciona um terceiro fator, o rendimento dos bens, que ficou mais tarde conhecido como rendimento de conveniência. $\mathrm{O}$ autor disse que em circunstâncias normais os estoques de todos os bens possuem um rendimento e que este rendimento é uma compensação para o detentor do estoque, completou ainda com a implicação de que o rendimento marginal cai drasticamente com um aumento dos estoques e pode subir acentuadamente com uma redução dos estoques. Ele completa que se as expectativas forem incertas, a diferença entre o preço esperado e o preço corrente deve cobrir, além dos custos de manutenção, certo prêmio de risco, abordado pela teoria do "normal backwardation", proposta por Keynes (1930).

$\mathrm{Na}$ mesma linha de pensamento da teoria da estocagem inicialmente discutida por Kaldor (1939), o trabalho de Working (1948) analisa a relação intertemporal de preços e relata que as discrepâncias de preços de uma data para outra devem representar a recompensa econômica direta para o serviço de estoque-transporte (custos de manutenção) da mercadoria, além de que as relações entre os preços para entrega em duas datas diferentes são comumente consideradas como dependentes do custo de realizar estas ações. $\mathrm{O}$ autor faz referência a esse diferencial de preço como sendo o "retorno necessário para a estocagem", ou seja, a recompensa econômica por armazenar o produto e ele completa que esta teoria das relações de preços intertemporais sob a condição de suprimentos abundantes ou superabundantes tem as propriedades comuns a todas as teorias de retorno para um serviço econômico. Se o retorno de um serviço for determinado livremente e competitivamente, ele variará de acordo com as condições de demanda e oferta, que é o caso dos retornos de armazenagem de trigo. Se os estoques a serem armazenados forem excepcionalmente grandes, o retorno para o transporte de trigo pode exceder o custo de armazenagem, conforme calculado convencionalmente. Já se os estoques forem moderados, a concorrência entre empresas com instalações de estocagem tende a resultar numa estocagem que será fornecido para um retorno bastante pequeno por unidade armazenada de soja, ou até negativo (WORKING, 1948).

Em uma versão baseada na otimização da teoria da estocagem, Deaton e Laroque (1992) aplica o modelo padrão de estocagem competitivo de expectativas racionais ao estudo de treze mercadorias, e concluem que os estoques atuam como "amortecedores", pois ajudam a absorver os choques da demanda e da oferta de preços. Dessa forma, fornecem evidências empíricas de que esse insight ajuda a explicar a correlação comumente observada nos preços das commodities.

Os retornos de conveniência estão inversamente relacionados com o nível de estoque, e a teoria da estocagem implica que as condições de oferta e demanda afetam não só as variações e correlações dos preços à vista e futuro, mas também o spread entre os preços spot e futuros, ou seja, da base (NG, PIRRONG; 1994). Para testar essas implicações, foi empregado um modelo dinâmico bivariado por $\mathrm{Ng}$ e Pirrong (1994) no qual se fez uma estimativa usando dados sobre preços spot e futuros de metais industriais negociados na London Metal Exchange (LME) no período 1986-92. Os resultados para os metais industriais são consistentes com as previsões da teoria da estocagem.

A dinâmica de curto prazo dos preços, produção e estoques de commodities, bem como as fontes e os efeitos da volatilidade do mercado é abordada por Pindyck (2001), através da análise de dados do complexo de petróleo (óleo cru, óleo de aquecimento e gasolina). Ele explica como os preços, as taxas de produção e os níveis de estoque estão inter-relacionados e são determinados pelo equilíbrio em dois mercados interconectados: um mercado à vista para compras e vendas da commodity e um mercado de armazenagem. O equilíbrio nesses mercados afeta e é afetado por mudanças no nível de volatilidade dos preços.

No Brasil, a análise do comportamento da base e seus riscos pode ser observada nos trabalhos de 
Fontes, Castro Junior e Azevedo (2005), Fernandes, Lima e Aguiar (2005), Tonin e Alves (2007), Gavotti (2012). Eles relacionam seu comportamento com o nível de estoque da mercadoria mensurado pela época do ano associada à safra. Já os trabalhos que testaram a teoria do backwardation, ou do prêmio de risco, foram realizados por de Santos (1998), Ende (2002), Pereira (2009), Sykora (2013), que, em suma, apresentam conclusões controversas com mais trabalhos em favor do backwardation, também suscetíveis à mercadoria e períodos analisados. Por sua vez, Corsini e Ribeiro (2008) e Pinto (2015) abordam especificamente a teoria da estocagem e concluem que o benefício de conveniência marginal varia com o tempo é que função decrescente do nível de estoque.

Nesta linha de pesquisa, alguns estudos merecem destaque. Barros e Aguiar (2005) analisaram o comportamento da base de café espécie arábica, visando ajudar o estabelecimento de estratégias de hedge. Os autores identificaram que há oportunidades de ganho tanto para hedgers de venda quanto de compra, porém as oportunidades de estratégias de hedge de compra são poucas e a lucratividade é ainda menor, isto em relação às estratégias de hedge de venda. Além disso, os autores encontraram que os contratos futuros com vencimento nos meses que antecedem a nova safra de maio apresentaram os maiores riscos de base devido ao fato de se terem maiores incertezas sobre as colheitas.

Por meio da realização de um cálculo de indicador de eficiência para o contrato futuro de boi gordo da BM\&F-BOVESPA, Abitante (2008) verificou a existência de uma ligação estatística entre o mercado spot e futuro de boi gordo negociados como commodities - na Bolsa de Mercadorias e Futuros (BM\&F-BOVESPA) e na Chicago Board of Trade (CBOT). Para o mercado de boi gordo, foram encontradas evidências de cointegração entre os preços spot e os contratos com vencimento em março, abril, setembro, outubro e novembro de 2005. No caso do contrato de soja da BM\&F-BOVESPA, a cointegração foi detectada nos vencimentos de abril, maio e novembro de 2005 . O contrato de soja da CBOT apresentou cointegração nos vencimentos de janeiro, março, setembro e novembro de 2005 . O indicador de eficiência do contrato futuro de boi gordo mostrou-se elevado, indicando que o mesmo pode auxiliar na descoberta de preço desta commodity.

Já Moraes, Lima e Melo (2009) realizaram testes sobre a hipótese de que os preços futuros são preditores não-viesados (sem viés) dos preços à vista a partir da hipótese conjunta de que os mercados são eficientes e que não existe prêmio ao risco. Afirmam os referidos autores que na presença de prêmio ao risco, a hipótese de não viés pode ser rejeitada mesmo quando o mercado é eficiente, então testa-se a eficiência do mercado futuro brasileiro do boi gordo na presença de prêmio ao risco, usando técnicas de cointegração. Como resultado, encontrou-se que o mercado futuro do boi gordo é eficiente e não-viesado no longo prazo, independente da presença de prêmio ao risco, ou seja, preços de contratos futuros podem ser considerados estimadores dos preços a vista.

Silva e Takeuchi (2010) testaram a hipótese de eficiência relativa dos mercados futuro e à vista (spot) de açúcar, para dois horizontes de previsão, em contraposição à hipótese de arbitragem de commodities. Os autores explicam que, na data de vencimento de um contrato, o preço futuro deve convergir para o preço spot (à vista) - ocorrendo tal situação, diz-se que o mercado é eficiente. A verificação da hipótese de eficiência é necessária para que não haja a possibilidade de arbitragem, ou seja, a obtenção de lucro sem risco por meio da realização de negociações simultâneas em dois ou mais mercados. Se o preço futuro for maior que o preço spot na data de vencimento, um participante do mercado poderia comprar o ativo à vista e vendê-lo no mercado futuro, auferindo lucros sem risco, arbitrando.

Silveira, Maciel e Ballini (2014) avaliaram a influência das negociações e da volatilidade dos preços futuros sobre a volatilidade dos preços à vista nos mercados de café arábica e de boi gordo no

Nucleus,v.15,n.2,out.2018 
Brasil através das técnicas de causalidade de Granger, decomposição da variância do erro de previsão, pela metodologia do Vector Auto-Regressive (VAR), e também causalidade na variância, baseados na função de correlação cruzada e no multiplicador de Lagrange. Os resultados mostraram que variações não esperadas do volume de negociação e variabilidade dos preços futuros alteraram o padrão de volatilidade dos respectivos mercados spot.

Mais recentemente, Joseph, Irwin e Garcia (2015) investigaram a existência da chamada curva de Working e os rendimentos de conveniência com preços a vista e futuro, com dados de estoque da CBOT para milho soja e trigo e KCBT (Kansas) para trigo com dados de 1990 a 2010. Foram utilizadas duas medidas de spread (base) - os futuros e a vista e dois futuros - contra os estoques entregues na primeira sexta de entrega. A estocagem na presença de backwardation é presente tanto em termos da porcentagem de observações e da magnitude dos estoques. A curva de Working foi observada mais claramente na commodity de trigo e de soja, e em todos os casos, os estoques declinam à medida que o spread cai, portanto existe uma relação positiva entre os spreads e os estoques, sugerindo que os locais terminais também possuem estoques para estocagem e conveniência.

Por sua vez, Milonas e Paratsiokas (2017) examinam a existência de rendimentos de conveniência nos preços da eletricidade com a utilização de um modelo em que as mudanças na base da eletricidade estão diretamente relacionadas a mudanças no nível de estocagem do combustível e o rendimento de conveniência do combustível, usando dados dos mercados de eletricidade e gás natural dos EUA durante o período 2004-2014. Observou-se que um baixo estoque nos mercados de combustíveis fósseis pode estar associado com escassez de suprimentos, principalmente durante períodos de condições climáticas adversas. Sua pesquisa ilustra o papel da estocagem na mitigação da volatilidade dos preços em todo o mercado da energia através da capacidade do mercado para responder às mudanças súbitas da demanda ou da oferta. Os resultados, portanto, mostram uma relação negativa entre a base da eletricidade e a conveniência do combustível dando apoio ao argumento de que mercadorias não armazenáveis incorporam rendimentos de conveniência.

A partir do contexto das pesquisas encontradas, tem-se como objetivo desta pesquisa analisar o comportamento recente da base nos contratos futuros de soja negociados na BMF\&BOVESPA, verificar se ela apresenta sazonalidade, e qual o impacto que possui as variáveis de estocagem, são elas o custo de oportunidade do capital, o custo de estocagem e o benefício de conveniência, as duas últimas são ambas afetadas pelo nível de estoque. A próxima seção trata da metodologia aplicada pelo estudo, será aplicada uma metodologia similar à de Fama e French (1987) para testar o impacto das variáveis de estocagem sobre a base nos contratos futuros de soja da BM\&F-BOVESPA.

\section{METODOLOGIA}

Com relação à classificação metodológica adotada nesta pesquisa, o método empregado foi o indutivo. Para Kerlinger (1980, p. 129), o método indutivo consiste em enumerar os enunciados sobre o fenômeno que se quer pesquisar e, por meio da observação, procurar apresentar algo novo que está presente na ocorrência do fenômeno. Já com relação aos procedimentos utilizados, esta pesquisa pode ser classificada como um levantamento. De acordo com Gil (2002, p. 50), procede-se ao levantamento quando são reunidas informações de uma amostra significativa da população, de forma a se poder analisar, mediante análise quantitativa posterior, o problema proposto. Por fim, com relação ao seu plano, esta é uma pesquisa descritiva. Hair Jr. et al. (2005, p. 83) definem as pesquisas descritivas com aquelas que 
descrevem alguma situação por meio da mensuração de um determinado evento ou atividade, neste caso, o diferencial entre o preço à vista e preço futuro da soja na BM\&F-Bovespa.

\subsection{Dados e Amostra}

A amostra coletada para construção da base do trabalho possui periodicidade diária, totalizando 842 observações. O período da base de dados inicia-se em 28/10/2013 até 27/03/2017. Optou-se por analisar os últimos cinco anos de contratos de soja, com a intenção de captar comportamentos recentes da variável base, que é a diferença entre o preço futuro e o preço spot. Além disso, com periodicidade diária somada a cinco anos de contratos formados, fornece observações suficientes para que os testes estatísticos tenham robustez.

As informações referentes ao preço spot e ao preço futuro dos contratos de soja foram coletadas no software Thomson Reuters ${ }^{\circledR}$, que possui informações referentes aos Minicontratos Futuros de Soja CME (SJC) da BM\&FBOVESPA. As informações referentes a taxa de juros dos certificados de depósitos interbancários (CDI) foram coletadas a partir da base de dados da Central de Custódia e de Liquidação Financeira de Títulos (CETIP).

\subsection{Variáveis}

A variável utilizada para representar a base neste trabalho é a mesma utilizada por Fama e French (1987), e pode ser observada na equação 2 .

$$
\text { - } \quad \text { Base }=\frac{F(t, T)-S(t)}{S(t)}
$$

Como proxy para o preço spot (à vista), $S(t)$, foi utilizado o preço futuro do contrato mais próximo do vencimento. Já para o preço futuro, $F(t, T)$, foi utilizado o preço do contrato com vencimento seis meses posterior ao preço spot, portanto a base ou a diferença temporal é de seis meses. A variável base foi construída de forma a sempre possuir o intervalo fixo de seis meses, para alcançar este objetivo e considerando a periodicidade diária, os dois preços coletados no dia deveriam ser de contratos distintos com vencimentos separados pelo intervalo temporal de seis meses. Por exemplo, para definir o valor da base para determinado dia foi utilizado como proxy para o preço spot o preço de fechamento do dia do contrato mais próximo do vencimento, que foi subtraído do preço do contrato com vencimento em seis meses. Segundo a BM\&FBOVESPA, os contratos possuem data de encerramento no segundo dia útil anterior ao mês de vencimento, ou seja, no final do mês anterior. A variável "base" foi calculada como variação percentual, assim como em Fama e French (1987), sendo pela diferença entre o preço futuro e o preço spot, divido pelo preço spot.

Ainda sobre a base, a mesma metodologia aplicada por Fama e French (1987) foi utilizada quanto à utilização da proxy de preço futuro na maturidade para representar o preço à vista, assegurou que os preços fossem retirados do mesmo local e ao mesmo tempo, evitando viés quanto à coleta das informações dos contratos. A periodicidade diária dos dados possibilitou que para qualquer dia que for coletado a variável Base, tenha-se o intervalo temporal fixo de seis meses.

A taxa de juros, que representa o custo de oportunidade do capital dos agentes de mercado, foi calculada pela taxa de juros dos certificados de depósitos interbancários (CDI). A taxa do CDI coletado foi diária anualizada, porém com o intuito de compreender o mesmo intervalo temporal da variável Base, esta

Nucleus,v.15,n.2,out.2018 
variável foi semestralizada. Com o objetivo de testar a hipótese da teoria da estocagem, espera-se que o $\beta$ seja positivo, ou seja, a variável Base deve variar de forma diretamente proporcional à taxa de juros CDI.

As dummies sazonais são uma maneira de capturar a variação nos retornos de conveniência devido à sazonalidade na produção (FAMA; FRENCH, 1987). Para esta pesquisa, foram estimados dois modelos. O primeiro utilizou a mesma variável estabelecida por Fama e French (1987), onde os valores 1,0 foram utilizados para os meses de maturação ou vencimento do contrato, como o dado da pesquisa é diário, o valor 1,0 foi repetido diariamente no mês de maturação do contrato, o valor 0,0 foi utilizado para os dias dos meses que o contrato não está em maturidade.

O segundo modelo estimado pelo trabalho estabeleceu as dummies sazonais com base no período mais usual de colheita, ou seja, essa dummy proposta pelo trabalho visa capturar o estoque do produto, e desta forma ela captura também o custo de estocagem e o rendimento de conveniência. Pela teoria, o custo de estocagem é diretamente proporcional ao estoque e o rendimento de conveniência é inversamente proporcional. Neste caso, a construção da variável foi baseada nas datas mais usuais de plantio e colheita da soja nos Estados Unidos da América (EUA). O Minicontrato Futuro de Soja CME (SJC) da BM\&FBOVESPA tem seu preço referenciado aos contratos futuros de soja da bolsa de Chicago (CME), assim a dummy sazonal proposta pelo trabalho mensurou os períodos de colheita da safra americana na tentativa de mensurar o nível de estoque mundial do produto caracterizado pela safra e entressafra do mercado como um todo.

Segundo a própria BM\&FBOVESPA, o Futuro de Soja do CME faz parte da gama de produtos da parceria com o CME Group. O preço do Contrato Futuro de Soja divulgado pelo CME Group é amplamente utilizado como referência para a negociação da commodity e de seus derivados em mercados internacionais. A criação deste derivativo possibilitou ao investidor brasileiro acessar produtos referenciados nesse preço sem ter acesso direto ao mercado norte-americano, sua cotação difere do seu contrato de referência da Bolsa de Chicago, o qual é cotado em USD/bushels, no entanto, utiliza-se o mesmo preço de ajuste do contrato negociado no mercado norte-americano.

Para estabelecer os valores das dummies foi utilizado o relatório da USDA Field Crops Usual Planting and Harvesting Dates de outubro de 2010 dos EUA (USDA, 2010), que apresentou o calendário exposto na Tabela 1 abaixo, como sendo as datas mais usuais de plantio e colheita da soja nos EUA. 
Tabela 1 - Datas de plantio e colheita de Soja nos EUA.

Soybean Usual Planting and Harvesting Dates - States

\begin{tabular}{|c|c|c|c|c|c|c|c|}
\hline \multirow{2}{*}{ State } & \multirow{2}{*}{$\begin{array}{c}2009 \\
\text { Harvested } \\
\text { acres }\end{array}$} & \multicolumn{3}{|c|}{ Usual planting dates } & \multicolumn{3}{|c|}{ Usual harvesting dates } \\
\hline & & Begin & Most active & End & Begin & Most active & End \\
\hline & (1,000 acres) & & & & & & \\
\hline Alabama ........ & 430 & Apr 15 & May 25 - Jun 25 & Jul 3 & Sep 3 & Oct 28 - Nov 28 & Dec 15 \\
\hline 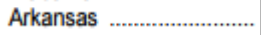 & 3,270 & Apr 19 & May 5 - Jun 22 & Jul 5 & Sep 10 & Sep 29 - Nov 13 & Nov 26 \\
\hline Delaware ..... & 183 & May 11 & May 30 - Jun 28 & Jul 11 & Oct 5 & Oct 22 - Nov 14 & Nov 25 \\
\hline Florida ................ & 34 & Apr 20 & May 1 - Jun 15 & Jul 1 & Oct 1 & Oct 15 - Nov 25 & Dec 1 \\
\hline Georgia ......... & 440 & May 5 & May 17 - Jun 26 & Jul 5 & Oct 11 & Oct $25-$ Dec 8 & Dec 17 \\
\hline Illinois ........ & 9,350 & May 2 & May 8 - Jun 12 & Jun 24 & Sep 19 & Sep 26 - Oct 26 & Nov 7 \\
\hline 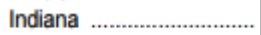 & 5,440 & May 1 & May 5 - Jun 10 & Jun 25 & Sep 20 & Oct 1 - Nov 1 & Nov 10 \\
\hline 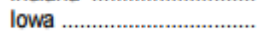 & 9,530 & May 2 & May 8 - Jun 2 & Jun 16 & Sep 21 & Sep 28 - Oct 20 & Oct 31 \\
\hline Kansas ........ & 3,650 & May 5 & May 15 - Jun 20 & Jul 1 & Sep 20 & Oct 1 - Nov 1 & Nov 15 \\
\hline Kentucky ................... & 1,420 & May 4 & May 16 - Jun 27 & Jul 7 & Sep 25 & Oct 10 - Nov 14 & Nov 25 \\
\hline Louisiana .... & 940 & Apr 18 & Apr 23 - Jun 4 & Jun 16 & Aug 28 & Sep 3 - Oct 25 & Oct 31 \\
\hline Maryland ..... & 475 & May 11 & May 28 - Jun 26 & Jul 16 & Oct 5 & Oct $18-$ Nov 15 & Dec 1 \\
\hline Michigan ... & 1,990 & May 2 & May 11 - Jun 9 & Jun 18 & Sep 25 & Oct 3 - Nov 3 & Nov 13 \\
\hline Minnesota ... & 7,120 & May 2 & May 8 - Jun 2 & Jun 13 & $\operatorname{Sep} 20$ & Sep 27 - Oct 20 & Oct 31 \\
\hline Mississippi .... & 2,030 & Apr 19 & Apr 26 - May 31 & Jun 17 & Sep 10 & Sep 13 - Oct 31 & Nov 9 \\
\hline 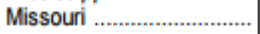 & 5,300 & May 2 & May 13 - Jun 24 & Jul 4 & Sep 25 & Oct 3 - Nov 8 & Nov 23 \\
\hline Nebraska .................. & 4,760 & May 5 & May 11 - May 31 & Jun 8 & Sep 23 & Sep 29 - Oct 24 & Nov 2 \\
\hline New Jersey ............ & 87 & May 10 & May 20 - Jul 1 & Jul 10 & Oct 1 & Oct $20-$ Nov 10 & Nov 15 \\
\hline New York ............. & 254 & May 12 & May 19 - Jun 22 & Jun 29 & Sep 27 & Oct 7 - Nov 14 & Nov 20 \\
\hline North Carolina ....... & 1,750 & May 1 & May 20 - Jun 30 & Jul 20 & Oct 10 & Nov 10 - Dec 5 & Dec 20 \\
\hline North Dakota & 3,870 & May 7 & May 14 - Jun 3 & Jun 11 & Sep 17 & Sep 24 - Oct 21 & Nov 5 \\
\hline Ohio .................... & 4,530 & Apr 26 & May 3 - May 30 & Jun 10 & $\operatorname{Sep} 23$ & $\operatorname{Sep} 30$ - Oct 31 & Nov 12 \\
\hline Oklahoma & 390 & Apr 15 & Apr 27 - Jun 27 & Jul 9 & Sep 9 & Sep 22 - Nov 20 & Dec 1 \\
\hline Pennsylvania .................. & 445 & May 10 & May 20 - Jun 10 & Jul 5 & Oct 5 & Oct $20-$ Nov 10 & Nov 30 \\
\hline 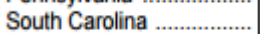 & 565 & May 10 & May 27 - Jun 27 & Jul 11 & Oct 20 & Nov 10 - Dec 10 & $\operatorname{Dec} 30$ \\
\hline South Dakota ................... & 4,190 & May 8 & May 15 - Jun 11 & Jun 21 & Sep 22 & Sep 28 - Oct 24 & Nov 3 \\
\hline Tennessee ............................. & 1,530 & May 5 & May 15 - Jun 25 & Jul 5 & Sep 25 & Oct 5 - Nov 20 & Nov 30 \\
\hline 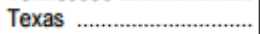 & 190 & Mar 24 & Mar 30 - May 30 & Jun 12 & Aug 18 & Aug 22 - Oct 17 & Nov 7 \\
\hline Virginia ....................... & 570 & May 5 & May 15 - Jul 3 & Jul 9 & Oct 4 & Oct 16 - Nov 28 & Dec 4 \\
\hline West Virginia .................... & 19 & May 5 & May 10 - Jun 30 & Jul 5 & Sep 25 & Oct 5 - Nov 30 & $\operatorname{Dec} 1$ \\
\hline 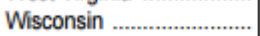 & 1,620 & May 7 & May 12 - Jun 5 & Jun 14 & Sep 29 & Oct 4 - Oct 29 & Nov 8 \\
\hline
\end{tabular}

Fonte: Relatório da USDA Field Crops Usual Planting and Harvesting Dates (USDA, 2010).

O período indicado como o começo da colheita nos EUA é 28 de agosto e dura até 30 de dezembro, as dummies sazonais para o mercado americano assumiram a condição de oferta mínima de estoque a partir de setembro até fevereiro e escassez de estoque de março a agosto.

Dessa forma, o valor zero (0.0) foi assumido para os dias dos meses de setembro até fevereiro para representar abundancia de estoque, ou o período safra, e o valor um (1.0), para os dias dos meses de março a agosto para representar escassez de estoque, ou período entressafra. Dessa forma, espera-se que o coeficiente referente ao benefício da conveniência, mensurada pela proxy de estoque que é estabelecida pela dummy sazonal da produção, seja negativo, ou seja, que a base apresente comportamento negativo nos momentos de escassez do produto, e positivo nos momentos de oferta.

Pode-se dizer que a dummy sazonal captura também, mesmo que indiretamente, o efeito dos custos de estocagem. Uma vez que o preço de estocagem, que tem em si embutido o custo de estocagem, varia em função dos estoques, e que o preço de estocagem é determinado em um livre mercado através da concorrência daqueles que procuram fornecer serviços de armazenagem, e a partir de que a maioria dos custos para empresas de estocagem são fixos sob um ponto de vista de curto prazo e conjuntos (WORKING, 1948). Na escassez do produto, os rateios destes custos em menor quantidade de produtos aumentam o seu custo de estocagem unitário, por isso a proxy para estoque captura também os custos de estocagem, e por isso na fórmula original da estocagem a base é diretamente proporcional ao custo de estocagem e inversamente proporcional ao benefício da conveniência, e as duas últimas inversamente proporcionais entre si. 


\subsection{Modelos}

Para testar as duas hipóteses propostas pelo trabalho, relacionadas ao custo de oportunidade e ao benefício de conveniência, foi proposto o modelo referente à "teoria da estocagem", o mesmo estudado por Fama e French (1987). O modelo pode ser observado a partir da equação (3).

$$
\text { Base }_{t}=\beta_{0}+\beta_{1} \text { Taxa de Juros } C D I_{t}+\beta_{2} \text { Dummie Sazonal }_{t}+\varepsilon_{t}
$$

Em que:

- Base $_{t}$ : representa o preço base para os contratos de soja, e foi calculado pela diferença entre o preço futuro e o preço spot, divido pelo preço spot;

- Taxa de Juros $C D I_{t}$ : representa a proxy para o custo de oportunidade do capital dos agentes de mercado;

- Dummie Sazonal : representa a variável proxy que capta fatores sazonais no estoque de produção da soja.

O modelo proposto na equação (3) será estimado três vezes, a primeira delas sem a variável dummy sazonal, a segunda vez com a variável dummy proposta por Fama e French (1987), e, por fim, a variável dummy sazonal proposta pelo presente estudo. A principal diferença entre as duas últimas estimações está na divergência entre a variável dummy proposta por Fama e French (1987) e a variável dummy proposta pelo presente trabalho. A dummy utilizada por Fama e French (1987) considerou valores 1,0 se o contrato entrasse em maturidade naquele mês, se não, considerou valores 0,0 , levando em conta que as maturidades dos contratos são uma proxy para padrões de produção e demanda. Já a dummy proposta pelo trabalho considera o calendário de produção americana de soja de acordo com o relatório da USDA Field Crops Usual Planting and Harvesting Dates (USDA, 2010). As dummies sazonais para o mercado americano assumiram a condição de abundância de estoque a partir de setembro até fevereiro, e escassez de estoque de março a agosto, portanto, foi assumido valores 1,0 para representar escassez de estoque, e 0,0 para representar abundância.

Para as estimações referentes ao modelo proposto pela equação (3), serão realizados testes para verificar os pressupostos da metodologia de Mínimos Quadrados Ordinários (MQO). Dentre os testes, encontram-se: o teste para existência de multicolinearidade por meio do Fator de Inflacionamento de Variância (VIF), segundo Fávero (2015), se o VIF médio for maior que cinco, pode ser considerado que os coeficientes do modelo estimado possuem uma alta correlação; o teste de Breusch-Pagan e CookWeisberg para testar a hipótese de homocedasticidade dos resíduos, sob a hipótese nula do teste de que a variância dos resíduos é constante, assim caso a hipótese nula for rejeitada, a estimação da matriz de covariância deve ser robusta; e, por fim, o teste de normalidade da distribuição dos resíduos a fim de se observar a curva de normalidade das matrizes e demais detalhes estatísticos, como desvio padrão.

A próxima seção do trabalho apresenta os resultados das estimações propostas pelo modelo apresentado aqui, além dos testes estatísticos e as discussões dos resultados encontrados com os previamentes estabelecidos pela literatura. 


\section{RESULTADO E DISCUSSÃO}

\subsection{Estatísticas Descritivas}

As estatísticas descritivas apresentam um leque de estatísticas que auxiliam a análise dos resultados de cada variável previamente as estimações que serão realizadas pelo trabalho. Referente à variável base, variável que representa o fenômeno de pesquisa do estudo, pode ser observado que a média apresentou valor negativo de $-1,818 \%$, com valores por vezes negativos e por vezes positivos. $\mathrm{O}$ valor negativo observado indica que o preço à vista fica, em média, maior que o preço futuro, assim sob a ótica da teoria da estocagem há indícios de que, quando o estoque é baixo e o benefício da conveniência é grande, consequentemente, o preço à vista neste período poderá estar acima do preço futuro. Da mesma forma, o preço futuro se mostra abaixo do preço à vista, uma vez que tem vencimento após o início da colheita onde terá abundância do produto no mercado, fazendo com que o diferencial de preços, ou seja, a base seja negativa (backwardation).

Como pode ser observado no Gráfico 1 da subseção 4.2, há um período entre fevereiro e agosto de 2014 que a base atinge patamares negativos altos quando comparado ao período total da série, dessa forma a estatística de média pode ser afetada drasticamente por este período, cabendo assim ser analisada também a estatística da mediana, pois é uma estatística que reduz o impacto de períodos com valores extremos da série. De acordo com a Tabela 2 abaixo, a mediana apresentou um valor de $-0,226 \%$, valor menor que a média, ainda negativo. A série apresenta um valor relativamente alto de desvio padrão, atingindo um valor mínimo de -18,047\%, em maio de 2014, e máximo de 1,98\%, em fevereiro de 2017.

Tabela 2 - Estatísticas Descritivas das Variáveis do Modelo.

\begin{tabular}{l|cccc}
\hline \multicolumn{1}{l}{ Estatísticas } & BASE & CDI 6 Meses & Dummy Fama & Dummy Trabalho \\
\hline Média & $-1,818 \%$ & $6,093 \%$ & 0,56 & 0,47 \\
Mediana & $-0,226 \%$ & $6,358 \%$ & 1,00 & 0,00 \\
Desvio Padrão & $4,747 \%$ & $0,752 \%$ & 0,50 & 0,50 \\
Mínimo & $-18,047 \%$ & $4,537 \%$ & 0,00 & 0,00 \\
Máximo & $1,980 \%$ & $6,836 \%$ & 1,00 & 1,00 \\
Observações & 842 & 842 & 842 & 842 \\
\hline
\end{tabular}

Legenda: Base: representa a variável proxy para o preço base para os contratos de soja, e foi calculado pela diferença entre o preço futuro e o preço spot, divido pelo preço spot; CDI 6 meses: representa a proxy para o custo de oportunidade do capital dos agentes de mercado; Dummy Fama: é a variável proxy que captura fatores sazonais do estoque de produção da soja no mercado, esta variável foi proposta pelo trabalho de Fama e French (1987); Dummy Trabalho: é a variável proxy proposta pelo presente trabalho que captura fatores sazonais do estoque de produção da soja no mercado.

Fonte: Elaborado pelos Autores.

Ainda em relação à Tabela 2, porém agora analisando a variável CDI 6 meses, proxy para o custo de oportunidade dos agentes de mercado, a variável apresentou uma média de 6,093\%, e sua mediana ficou próxima a variável atingindo $6,358 \%$. O desvio padrão da variável é relativamente pequeno quando comparado a variável base, e o valor mínimo observado atingiu 4,537\%, enquanto o máximo atingiu $6,836 \%$. 
A Tabela 3 apresenta a matriz de correlação entre as variáveis do modelo proposto pela equação (3). Pode ser observado que não há alta correlação entre as variáveis do modelo, fornecendo indícios de inexistência de multicolinearidade entre as variáveis, porém ainda é necessário realizar o teste VIF proposto na seção da metodologia.

Espera-se, de acordo com a primeira hipótese proposta pelo trabalho, uma relação positiva entre a variável proxy para o custo de oportunidade, CDI 6 meses, e a variável Base. A matriz de correlação apresentou uma correlação positiva entre ambas variáveis, no valor de 0,4594. Esse coeficiente positivo fornece indícios estatísticos que há uma relação diretamente proporcional entre ambas variáveis. Cabe ressaltar que a correlação não dá indícios de causa e efeito, apenas inferência quanto ao sinal, comportamento, entre variáveis.

Quanto à segunda hipótese proposta pelo trabalho, de que o benefício da conveniência impacta negativamente a base dos contratos futuros de soja no Brasil, a correlação das duas variáveis dummies com a base é negativa, porém a correlação entre a base e a dummy calculada pela metodologia de Fama e French (1987) é menor do que a correlação com a dummy proposta pelo trabalho.

Tabela 3 - Matriz de Correlação entre as Variáveis do Modelo.

\begin{tabular}{l|cccc}
\hline Correlograma & BASE & CDI 6 meses & Dummy Trabalho & Dummy Fama \\
\hline BASE & 1,0000 & & & \\
CDI 6 meses & 0,4594 & 1,0000 & & \\
Dummie Trabalho & $-0,5201$ & 0,0969 & 1,0000 & \\
Dummie Fama & $-0,0257$ & 0,0681 & 0,1889 & 1,0000 \\
\hline
\end{tabular}

Legenda: Base: representa a variável proxy para o preço base para os contratos de soja, e foi calculado pela diferença entre o preço futuro e o preço spot, divido pelo preço spot; CDI 6 meses: representa a proxy para o custo de oportunidade do capital dos agentes de mercado; Dummy Fama: é a variável proxy que captura fatores sazonais do estoque de produção da soja no mercado, esta variável foi proposta pelo trabalho de Fama e French (1987); Dummy Trabalho: é a variável proxy proposta pelo presente trabalho que captura fatores sazonais do estoque de produção da soja no mercado.

Fonte: Autoria Própria.

A próxima subseção apresenta uma análise gráfica entre a variável base e variável dummy sazonal proposta pelo trabalho, com o intuito de verificar o comportamento das variáveis ao longo do tempo.

\subsection{Análise Gráfica das Variáveis}

A partir do Gráfico 1 da base, e apesar do curto período analisado, fica claro, que independente da época a base apresenta um comportamento sazonal, esta é uma informação relevante aos agentes de mercado que podem antecipar seu comportamento com base na sazonalidade da produção. 
Gráfico 1 - Variável Base com a dummy sazonal de estoque proposta pelo trabalho.

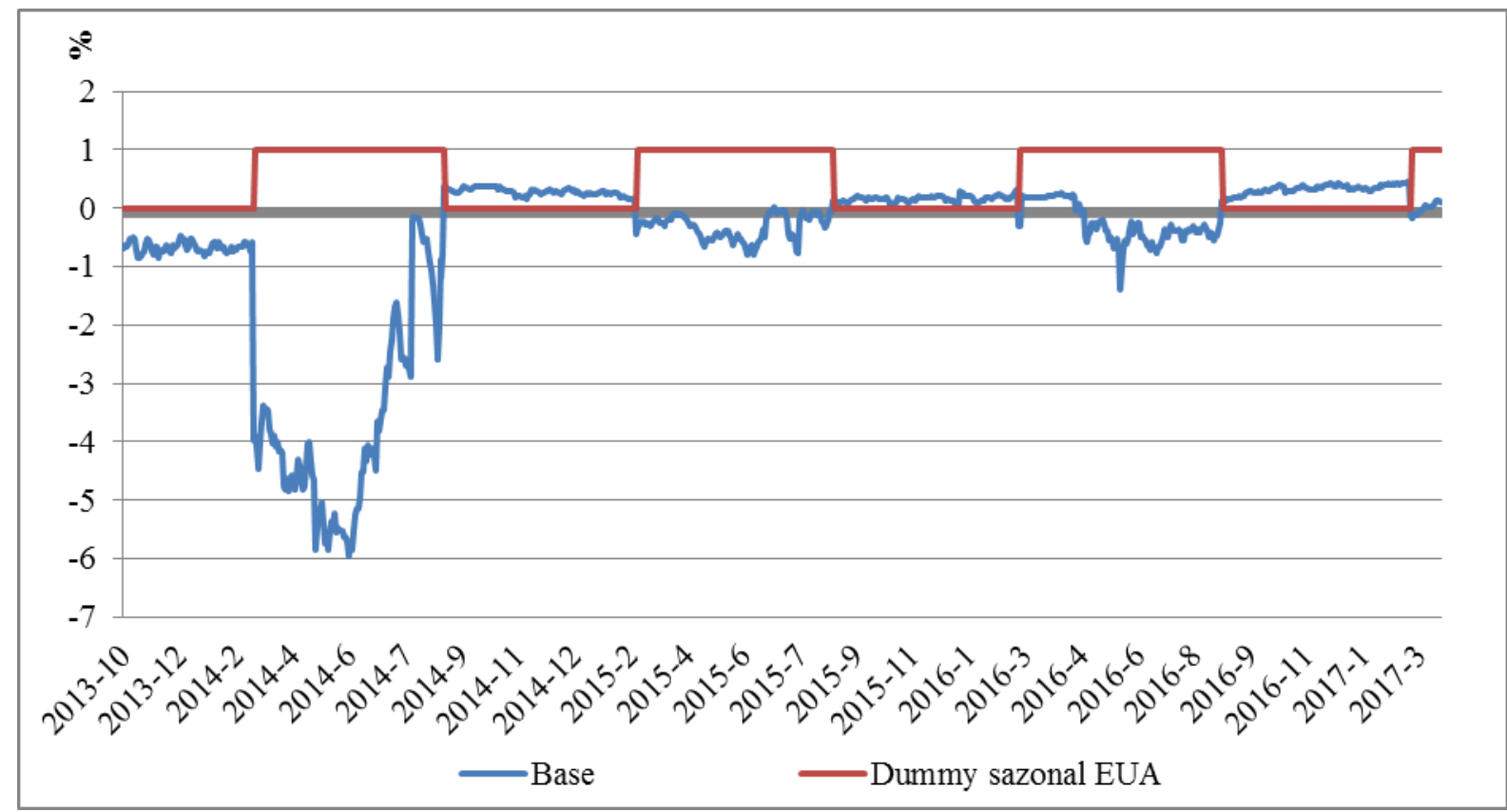

Fonte: Autoria Própria.

O período que vai de fevereiro a setembro de 2014 é caracterizado por uma forte queda da base, o período sugere que ela deveria ter um comportamento negativo, porém nao tão intenso, uma análise dos dados permite observar que os preços à vista nesse momento seguiram uma tendência de alta, devido à falta de produto no mercado, enquanto os preços futuros apresentaram forte queda, devido à projeção de boas safras, segundo o próprio Departamento de Agricultura dos Estados Unidos - USDA, a safra de soja de 2014 apresentou recordes históricos.

A partir do Gráfico 1, pode ser observado que a base, independente do ano, apresenta um comportamento sazonal, e esta é uma informação relevante aos agentes de mercado que podem tentar antecipar seu comportamento com expectativa na sazonalidade da produção de soja no mercado.

A variável que representa a dummy sazonal para estoque provê com uma informação ainda mais relevante, que é justamente a coincidência dos períodos de comportamento da base com a proxy para o estoque, a base se comporta quase fielmente aos períodos determinados pela existência ou não de estoque, entretanto, faz-se necessário o uso de análises estatísticas mais robustas para capturar o real efeito das variáveis explicativas, custos de oportunidade e benefício da conveniência, sobre a variável dependente, base.

\subsection{Resultados dos Modelos}

De acordo com a Tabela 4, pode ser observado que nos 3 modelos estimados, com resultados na Tabela 5, a estatística VIF apresenta valor médio menor que 5, valor que segundo Fávero (2015) indica que os coeficientes dos modelos estimados possuem uma baixa correlação, evidenciando a inexistência de problemas de multicolinearidade.

Referentes aos testes de normalidade propostos, a hipótese de que os resíduos da equação seguem uma distribuição normal é rejeitada. Sendo assim, segundo Fávero (2015), o p-valor e testes t e F 
não seriam válidos com a não observância da normalidade dos resíduos, porém, segundo Wooldridge (2010) essa violação é amenizada com a utilização de grandes amostras. No caso deste trabalho, a base de dados apresentou 842 observações de dados diários, portanto espera-se que o problema referente à normalidade dos resíduos seja amenizado.

Por fim, a estatística de teste da heterocedasticidade que testa o pressuposto de que os resíduos não apresentam correlação com qualquer variável explicativa do modelo foi rejeitado para os três modelos. De acordo com Fávero (2015), a presença de heterocedasticidade gera estimadores dos parâmetros não-viesados, porém ineficientes, o que acarreta problemas com os testes de hipótese das estatísticas $t$. Como correção para este problema, as estimações nos três modelos foram realizadas por meio da matriz de variância/covariância dos parâmetros robustas (matriz robusta).

Tabela 4 - Testes Estatísticos dos Modelos Estimados.

\begin{tabular}{l|c|c|c}
\hline Modelos & 1 & 2 & 3 \\
\hline Multicolinearidade & 1,00 & 1,01 & 1,00 \\
\hline VIF médio & 0,000 & 0,000 & 0,000 \\
\hline Normalidade & 0,000 & 0,000 & 0,000 \\
\hline Teste W de Shapiro-Wilk (Prob > z) & 384,19 & 365,84 & 376,09 \\
Teste W de Shapiro-Francia (Prob > z) & 0,000 & 0,000 & 0,000 \\
\hline Heterocedasticidade &
\end{tabular}

Fonte: Autoria Própria.

A partir da Tabela 5, pode ser observado as estimações propostas pelo modelo da equação (3). Inicialmente deve ser verificado a estatística $\mathrm{F}$, que indica se a combinação linear entre as variáveis explicativas afeta conjuntamente a variável dependente estimada pelo modelo. Nos três modelos estimados, a estatística rejeitou a hipótese nula de que a combinação linear dos estimadores é igual a zero (0). Portanto, os estimadores conjuntamente afetam a variável Base.

Analisando primeiramente o modelo 1, observa-se que assim como esperado para a relação entre a variável CDI 6 meses, proxy para o custo de oportunidade dos agentes de mercado, possui relação positiva e significante a um nível de $1 \%$ de significância. O primeiro modelo apresentou uma estatística de $\mathrm{R}^{2}$ igual a 0,2111, indicando que a variável proxy do custo de oportunidade dos agentes explica, aproximadamente, $21,1 \%$ das variações ocorridas na variável Base.

O segundo modelo foi estimado com a variável do CDI 6 meses, mais a variável proxy dummy proposta por Fama e French (1987) para representar o benefício da conveniência. Referente à variável proxy para o custo de oportunidade foi obtido o mesmo sinal, positivo e significante a $1 \%$. De acordo com a literatura estudada, a variável que capta o benefício da conveniência deve apresentar sinal negativo com a base. Na Tabela 4, nota-se que o sinal encontrado é negativo e significante a um nível de $10 \%$. A estatística do $\mathrm{R}^{2}$ ficou próxima da estatística encontrada no primeiro modelo, pois, houve um aumento do poder de explicação do modelo de apenas 0,32 p.p. ao ser inserido a dummy proposta pela metodologia do trabalho de Fama e French (1987). 
O último modelo estimado foi testado com uma variável dummy que também é utilizada como proxy para o estoque, associada ao rendimento de conveniência e custo de estocagem, porém, diferente da metodologia utilizada pelo trabalho de Fama e French (1987). A variável dummy proposta pelo trabalho foi construída com base no relatório da USDA Field Crops Usual Planting and Harvesting Dates de outubro de 2010 dos EUA, exposto na Tabela 1 na seção 3 de metodologia, que apresentou o calendário com as datas mais usuais de plantio e colheita da soja nos EUA.

A partir da nova variável proxy foi estimado o modelo 3 exposto na Tabela 5. A variável do CDI 6 meses apresentou coeficiente positivo e significante a $1 \%$, assim como nos dois modelos estimados anteriormente. A variável proxy dummy para o benefício da conveniência apresentou relação negativa estatisticamente significante a um nível de $1 \%$, nível menor e estatisticamente melhor quando comparado ao nível obtido pelo modelo dois. Observa-se uma estatística de $\mathrm{R}^{2}$ igual a 0,5329 , ou seja, as variáveis explicativas do modelo três explicam aproximadamente 53\% das variações que ocorrem na variável base. Assim, o modelo com a variável proxy dummy para o estoque proposto pelo trabalho aumentou o poder de explicação do modelo em 31,86 p.p. quando comparado ao segundo modelo estimado com a proxy para o benefício da conveniência pela metodologia de Fama e French (1987).

Tabela 5 - Resultados Estatísticos dos Modelos Propostos.

\begin{tabular}{|c|c|c|c|c|c|c|c|c|c|}
\hline \multirow{2}{*}{$\begin{array}{l}\text { Variável Dependente } \\
\text { Variáveis Independentes }\end{array}$} & \multicolumn{9}{|c|}{ BASE } \\
\hline & Coef. & Est. $\mathrm{t}$ & $p$-valor & Coef. & Est. t & $p$-valor & Coef. & Est. $\mathbf{t}$ & $p$-valor \\
\hline CDI 6 meses & 2,902 & $13,42 * * *$ & 0,000 & 2,926 & $13,66 * * *$ & 0,000 & 3,251 & $19,85^{* * *}$ & 0,000 \\
\hline Dummy Fama & & & & $-0,005$ & $-1,86^{*}$ & 0,063 & & & \\
\hline Dummy Trabalho & & & & & & & $-0,054$ & $-21,88 * * *$ & 0,000 \\
\hline Constante & $-0,195$ & $-13,50 * * *$ & 0,000 & $-0,193$ & $-13,34 * * *$ & 0,000 & $-0,191$ & $-19,14 * * *$ & 0,000 \\
\hline Modelos & & 1 & & & 2 & & & 3 & \\
\hline $\mathbf{N}$ & & 842 & & & 842 & & & 842 & \\
\hline Prob $>$ F & & 0,000 & & & 0,000 & & & 0,000 & \\
\hline $\mathbf{R}^{2}:$ & & 0,2111 & & & 0,2143 & & & 0,5329 & \\
\hline
\end{tabular}

Variáveis: Base: representa a variável proxy para o preço base para os contratos de soja, e foi calculado pela diferença entre o preço futuro e o preço spot, divido pelo preço spot; CDI 6 meses: representa a proxy para o custo de oportunidade do capital dos agentes de mercado; Dummy Fama: é a variável proxy que captura fatores sazonais do estoque de produção da soja no mercado, esta variável foi proposta pelo trabalho de Fama e French (1987); Dummy Trabalho: é a variável proxy proposta pelo presente trabalho que captura fatores sazonais do estoque de produção da soja no mercado. Rejeição da hipótese nula: ***nível de significância 1\%; **nível de significância 5\%; *nível de significância $10 \%$.

Fonte: Autoria Própria.

A partir dos testes estatísticos realizados e dos resultados encontrados podem ser realizadas inferências quanto às duas hipóteses propostas pelo trabalho, com o objetivo de responder a seguinte questão de pesquisa proposta pelo mesmo: a variável base é afetada pelas variáveis de estocagem?

Referente à primeira hipótese proposta por este estudo de que o custo de oportunidade dos agentes de mercado impacta positivamente a base dos contratos futuros de soja no Brasil, pode ser inferido que a relação esperada foi encontrada empiricamente. Dessa forma, um aumento no custo de oportunidade dos agentes de mercado, afeta de forma positiva a variável base, ou seja, se o custo de oportunidade dos agentes aumentar, o agente que comprou a soja com expectativa de venda no futuro precisa remunerar seu 
capital, com pelo menos a taxa de juros livre de risco que ele tinha ao usar seu capital para comprar a soja.

A segunda hipótese proposta, de que o benefício da conveniência impacta negativamente a variável base, não é rejeitada a partir das evidências estatísticas encontradas. Assim, pode ser inferido que um aumento no benefício da conveniência, que foi representada por uma variável proxy dummy que captura a variação nos estoques devido à sazonalidade na produção, leva a uma redução na base, ou seja, em períodos de baixo estoque de soja (alta conveniência), o preço spot é maior quando comparado ao preço futuro, porque o preço spot está alto pela escassez do produto, e preço futuro está mais baixo pois possui vencimento no período safra com maiores níveis de estoques. A redução da base é refletida pelo aumento do benefício de conveniência, pois é mais conveniente possuir o produto quando o seu estoque é baixo, e por isso o rendimento de conveniência tem sinal negativo no modelo.

O mesmo raciocínio pode ser aplicado para períodos de alto estoque, há uma diminuição do benefício de conveniência, assim o preço spot é menor quando comparado ao preço futuro, ou seja, o preço spot está baixo devido ao alto estoque, e o preço futuro mais alto, pois possui vencimento na entressafra, onde há escassez de produto.

A simples observação da base, assim como os testes estatísticos mostraram sazonalidades confiáveis para a soja, esses achados, assim como os encontrados nos trabalhos de Fama e French (1987), Brooks, Prokopczuk e Wu (2013) e Pinto (2015) validam empiricamente a teoria da estocagem.

$\mathrm{Na}$ próxima seção contém as considerações finais referentes aos resultados encontrados e apresenta as limitações da pesquisa, assim como sugestões para futuros trabalhos na área.

\section{CONSIDERAÇÕES FINAIS}

O principal objetivo deste trabalho foi analisar o comportamento da "base" nos contratos futuros da commodity agrícola soja no Brasil. A partir dos resultados encontrados que foram aplicados ao mercado brasileiro, observou-se uma gama de evidências que suportam a teoria da estocagem que foi proposta inicialmente por Kaldor (1939), Working (1948), Brennan (1958) e Telser (1958).

Em relação à evolução dos preços da base, constatou-se um comportamento sazonal, isto é, a base se mostra positiva em um período do ano, e negativa em outro, sendo que esses períodos estão fortemente relacionados aos períodos de produção sazonal relativo à safra anual. Esta evidência está de acordo com os achados identificados nos trabalhos aqui referenciados, segundo o qual a base é afetada pelo nível de estoque, que por sua vez afeta as variáveis de estocagem. Os trabalhos brasileiros que mostram o fortalecimento da base na safra são os trabalhos de Fontes, Castro Júnior e Azevedo (2005) e Fernandes, Lima e Aguiar (2005), para a atividade cafeeira, Tonin e Alvez (2007) para o milho e Maia e Aguiar (2010) para a soja.

Ainda sobre os valores da base, nota-se que o período anterior a agosto de 2014, é caracterizado fortemente por valores negativos, o que indica a presença de backwardation ou mercado invertido. De acordo com Sykora (2013), o mercado invertido, sob a perspectiva de custo de carregamento negativo, tem suas raízes na propagação instantânea dos choques de curto prazo sobre os preços spot. Este comportamento pode estar associado aos choques de preço ocorridos devido a quebras de safra a partir de adversidades climáticas no período. No entanto, após este período, o mercado se comportou de forma prevista pela teoria da estocagem, com valores positivo e negativos alternando-se anualmente de acordo com a sazonalidade da produção americana.

As análises estatísticas realizadas no trabalho testaram o impacto das variáveis de estocagem, dentre elas: o custo de oportunidade do capital e o benefício de conveniência, esta última variável derivada 
de possuir o estoque fisicamente. A análise realizada testou a base como variável dependente, sendo explicada pelo custo de oportunidade do capital e o benefício de conveniência. A principal relação observada é de que a base varia diretamente proporcional aos estoques e ao custo de oportunidade do capital, e inversamente proporcional ao benefício de conveniência, assim como observados nos trabalhos de Fama e French (1987), Milonas e Thomadakis (1997), Nielsen e Schwartz (2004), Nakajima (2015), Joseph, Irwin e Garcia (2015), Dockner, Eksi e Rammerstorfer (2015), Milonas e Paratsiokas (2017), Kim, Kim e Heo (2017) e Nakajima (2017), além do trabalho brasileiro desenvolvido recentemente por Pinto (2015).

Os resultados encontrados estão em conformidade com a teoria da estocagem proposta por Working (1948), que a base é diretamente proporcional aos estoques. Em suma, no período safra, período ao qual se pressupõe alto estoque relativo, a grande oferta do produto leva o preço à vista a cair, já o preço futuro com vencimento na entressafra, período ao qual se pressupõe baixo estoque, tende a estar elevado. Dado o calculo da base como preço futuro menos preço a vista, tem-se que a base é positiva, ou maior. Em termos das variáveis da teoria da estocagem, na safra os custos de estocagem são altos, pois os armazéns estão cheios, já o rendimento de conveniência é baixo, pois é pouco conveniente possuir o produto quando os estoques são altos. Por outro lado, na entressafra, a base tende a ser negativa ou menor, pois o preço a vista está alto dado o baixo estoque e o preço futuro com vencimento na safra, onde se pressupõe alto estoque, tende a estar baixo. Com relação às variáveis da estocagem, os custos de armazenamento estão baixos, pois os armazéns estão vazios, e o rendimento de conveniência é alto, pois é muito conveniente possuir o produto quando os estoques são baixos.

Os resultados sugerem que o comportamento da base nos contratos de soja no Brasil está mais relacionado com a safra de soja americana, ainda o maior produtor de soja do mundo. Além disso, o mercado futuro na BM\&FBOVESPA é fortemente relacionado ao mercado americano na CBOT, pois utilizam os mesmos ajustes de preço.

Com relação às estratégias de operação neste mercado, o momento em que a base está maior, ou então, ela excede os custos de estocagem (contango), Fernandes, Lima e Aguiar (2005) afirma que pode ser interessante para o agricultor fazer um hedge de venda, visando o estreitamento da base. No momento em que a base é menor, ou até negativa (backwardation), subentende-se que o mercado oferece um prêmio de risco ao especulador, sendo interessantes praticar posições de compra no mercado futuro, visando o aumento dos valores da base.

Os resultados aqui encontrados são úteis aos produtores de soja, as empresas que utilizam a soja como input - insumos, entrada para alimentar processos produtivos - para a produção de derivados e, também, aos agentes que operam neste mercado, pois podem antecipar a evolução futura de preços e realizar suas operações de forma mais eficiente, seja ela para fim de cobertura de risco (hedge) ou de caráter especulativa.

Para estudos futuros, cabem análises com outras periodicidades, que estiveram fora do escopo do presente trabalho, além de análises da base para outras commodities também importantes ao mercado brasileiro, com o objetivo de identificar padrões específicos para cada tipo de commoditiy, além de trabalhos que utilizem modelos baseados nas duas teorias, tanto a da estocagem, como a do backwardation. 


\section{REFERÊNCIAS}

ABITANTE, K. G. Co-integração entre os mercados spot e futuro: evidências dos mercados de boi gordo e soja. Revista de Economia e Sociologia Rural, v. 46, n. 1, p. 75-96, 2008.

BARROS, Á. de M.; AGUIAR, D. R. D. Gestão do risco de preço de café arábica: uma análise por meio do comportamento da base. Revista de Economia e Sociologia Rural, v. 43, n. 3, p. 443-464, 2005.

BIGNOTTO, E. C.; BAROSSI-FILHO, M.; SAMPAIO, R. Gestão do risco de mercado em organizações do agronegócio. Resenha BM\&F-BOVESPA, v. 4, n. 161, p. 26-32, 2004.

BRENNAN, M. J. The supply of storage. The American Economic Review, v. 48, n. 1, p. 50-72, 1958.

BROOKS, C.; PROKOPCZUK, M.; WU, Y. Commodity futures prices: More evidence on forecast power, risk premia and the theory of storage. The Quarterly Review of Economics and Finance, v. 53, n. 1, p. 73-85, 2013.

CORSINI, F. P.; RIBEIRO, C. de O. Dinâmica e previsão de preços de commodities agrícolas com o filtro de Kalman. Anais do Encontro Nacional de Engenharia de Produção, 2008.

DEATON, A.; LAROQUE, G. On the behaviour of commodity prices. The Review of Economic Studies, v. 59, n. 1, p. 1-23, 1992.

DOCKNER, E. J.; EKSI, Z.; RAMMERSTORFER, M. A Convenience Yield Approximation Model for Mean-Reverting Commodities. Journal of Futures Markets, v. 35, n. 7, p. 625-654, 2015.

DUARTE JÚNIOR, A. M. Risco: definições, tipos, medição e recomendações para seu gerenciamento. São Paulo: Atlas, 2001.

ENDE, M. V. Comportamento dos preços dos contratos agropecuários negociados na BM\&F: a hipótese de "normal backwardation" no mercado futuro brasileiro. Dissertação de Mestrado em Administração - Escola de Administração, Universidade Federal do Rio Grande do Sul, Porto Alegre, 2002

FÁVERO, L.P. Análise de Dados. 1. ed. São Paulo: Elsevier, 2015

FAMA, E. F.; FRENCH, K. R. Commodity futures prices: Some evidence on forecast power, premiums, and the theory of storage. Journal of Business, v. 60, n. 1, p. 55-73, 1987.

FARHI, M. et al. O futuro no presente: um estudo dos mercados de derivativos financeiros. Tese de Doutorado - Instituto de Economia, Unicamp, Campinas, 1998.

FERNANDES, E. A.; LIMA, A. M. S.; AGUIAR, D. R. D.de. O Comportamento do Preço à Vista e Futuro de Café no Brasil: o Hedge como Opção de Redução de Risco. In: Congresso Sociedade Brasileira de Economia, Administração e Sociologia Rural (SOBER). 2005.

FONTES, R. E.; CASTRO JUNIOR, L. G. de; AZEVEDO, A. F. Estratégia de comercialização em mercados derivativos-descobrimento de base e risco de base da cafeicultura em diversas localidades de Minas Gerais e São Paulo. Ciência e Agrotecnologia, v. 29, n. 2, p. 382-389, 2005.

GAVOTTI, F. S. M. Oportunidades de hedge no mercado de açúcar: uma análise por meio da base. 2012. 66f. Dissertações de Mestrado Profissional em Agronegócios - Escola de Economia de São Paulo MPAGRO, São Paulo, 2012. 
GIL, A.C. Como elaborar projetos de pesquisa. 4. ed. São Paulo: Atlas, 2002. 175 p.

HAIR JÚNIOR., J.F.et al. Fundamentos de métodos de pesquisa em administração. Porto Alegre: Bookman, 2005. 471 p.

JOSEPH, K.; IRWIN, S. H.; GARCIA, P. Commodity Storage under Backwardation: Does the Working Curve Still Work? Applied Economic Perspectives and Policy, v. 38, n. 1, p. 152-173, 2015.

KALDOR, N. Speculation and economic stability. The Review of Economic Studies, v. 7, n. 1, p. 1-27, 1939.

KERLINGER, F. N. Metodologia da pesquisa em ciências sociais: um tratamento conceitual. EPU: Edusp, 1980.

KEYNES, J. M. Treatise on money: Pure theory of money. v.1, 1930.

MAIA, F. N. C. S.; AGUIAR, D. R. D. Estratégias de hedge com os contratos futuros de soja da Chicago Board of Trade. Gestão Produção, v. 7, n. 3. p. 617-626, 2010

MILONAS, N. T.; THOMADAKIS, S. B. Convenience yields as call options: an empirical analysis. Journal of Futures Markets, v. 17, n. 1, p. 1-15, 1997.

MORAES, A. S.; LIMA, R. C.; MELO, A. de S. Análise da eficiência do mercado futuro brasileiro de boi gordo usando co-integração. Revista de Economia e Sociologia Rural, v. 47, n. 3, p. 601-614, 2009.

NAKAJIMA, K. Commodity spot and futures prices under supply, demand, and financial trading. Browser Download This Paper, 2015.

NG, V. K.; PIRRONG, S. C. Fundamentals and volatility: Storage, spreads, and the dynamics of metals prices. Journal of Business, p. 203-230, 1994.

NIELSEN, M. J.; SCHWARTZ, E. S. Theory of storage and the pricing of commodity claims. Review of Derivatives Research, v. 7, n. 1, p. 5-24, 2004.

PEREIRA, L. M. Modelo de formação de preços de commodities agrícolas aplicado ao mercado de açúcar e álcool. 2009. Tese (Doutorado em Administração) - Faculdade de Economia, Administração e Contabilidade, Universidade de São Paulo, São Paulo, 2009.

PINDYCK, R. S. The dynamics of commodity spot and futures markets: a primer. The energy journal, v. 22, n. 3, p. 1-29, 2001.

PINTO, L. T. B. M. Estoques De Óleo Cru E O Benefício De Conveniência (Convenience Yield): Uma Análise Do Mercado Norte-Americano. 2015. Dissertação (Mestrado em Planejamento Energético) Instituto Alberto Luiz Coimbra de Pós-Graduação e Pesquisa de Engenharia, Universidade Federal do Rio de Janeiro, Rio de Janeiro, 2015.

SANCHES, A. C.; MICHELlON, E.; ROESSING, A. C. Os limites de expansão da soja. Informe GEPEC, v. 9, n. 1, 2004.

SANTOS, J. E. Normal backwardation é normal no mercado futuro brasileiro? Relatório de Pesquisa n ${ }^{\circ}$ 15/1998. Escola de Administração de Empresas de São Paulo, Fundação Getúlio Vargas, Núcleo de Pesquisas e Publicações, 1998. Disponível em:

http://gvpesquisa.fgv.br/sites/gvpesquisa.fgv.br/files/publicacoes/P00138_1.pdf

SILVA, R. da; TAKEUCHI, R. Mercados Futuro e à Vista de Açúcar: uma análise empírica de eficiência versus arbitragem. Revista de Economia e Sociologia Rural, v. 48, n. 2, p. 307-330, 2010. 
SILVEIRA, R. L. F.; MACIEL, L.; BALLINI, R. Derivativos sobre Commodities Influenciam a Volatilidade dos Preços à Vista? Uma análise nos mercados de boi gordo e café arábica no Brasil. Revista de Economia e Sociologia Rural, v. 52, n. 3, p. 417-436, 2014.

SYKORA, N. D. Preços de Commodities Agrícolas e o Comportamento de Mercado Invertido

(Backwardation): o caso da soja. 2013. Dissertações (Mestrado em Finanças e Economia Empresarial) Fundação Getúlio Vargas, Escola de Pós-graduação em Economia, Rio de Janeiro, 2013.

TELSER, L. G. Futures trading and the storage of cotton and wheat. Journal of Political Economy, v. 66, n. 3, p. 233-255, 1958.

TONIN, J. M.; ALVES, A. F. Análise de base para o milho na região de Maringá. Revista CesumarCiências Humanas e Sociais Aplicadas, v. 12, n. 1, 2007.

WOOLDRIDGE, J. M. Econometric Analysis of Cross Section and Panel Data. Cambridge: The MIT Press, 2010.

WORKING, H. Theory of the inverse carrying charge in futures markets. Journal of Farm Economics, v. 30, n. 1, p. 1-28, 1948. 